\title{
KODAK AND THE FUTURE OF ASTRONOMICAL PHOTOGRAPHY
}

\author{
D. MALIN \\ Anglo-Australian Observatory \\ P.O. Box 296 (167 Vimiera Road) \\ Epping, NSW 2121 \\ Australia
}

This is probably the first astronomical meeting with a serious photographic content where Kodak has not been represented. We had invited Gordon Brown who was once responsible for the scientific imaging market to come and talk to us about the availability of spectroscopic emulsions. However, I was told the Company no longer has a person responsible for scientific plates, a fact which I interpret with some foreboding and a great deal of sadness. It therefore falls to me to fill this part of the program with a statement that has been approved, or at least not contested, by Eastman Kodak.

The Eastman Kodak Company have had a commitment to the manufacture of special photographic emulsions for scientific purposes for nearly 75 years. The astronomical community is indeed fortunate that the first Director of Research, and the founder of the Eastman Kodak Research Laboratories before the First World War was C.E. Kenneth Mees.

It was Mees who encouraged his colleagues to prepare experimental quantities of emulsions specially designed to be efficient during long exposures at low light levels. This was not just to please astronomers; such exercises greatly improved the Company's understanding of the fundamental mechanisms of photographic sensitivity, and led to a stream of discoveries and ideas that were, and are still, being applied to consumer products today.

Unfortunately, we are now told that many of the specialised gelatins that are an essential ingredient in the exquisite sensitivity of many of the special emulsions are no longer available. This is because they were formulated many decades ago. Because the market for these products has dwindled, it is not possible for the Company to devote the research effort needed to find adequate substitutes, so we are now faced with the uncomfortable fact that many useful products on which we have relied for many years are to be discontinued.

When I sent the original text of this statement to Gordon Brown at Kodak in July it said bluntly that Spectroscopic Plates type 103a, type IIa and type 098-04 will never be made again. Brown replied that I had overstated the case somewhat, and that efforts to save these emulsions were being made. However, this morning I heard from Brown that these emulsions had indeed been discontinued. Since this group of products includes the orthochromatic sensitising, formerly type $D$, and the unsensitised emulsions, type $O$, loss of these products means that the photometric $B$ and $V$ bands are no longer available without special (and inefficient) composite filters used in conjunction with panchromatic materials.

In addition to these products, Type IV-N, the splendid, fine-grain, near infrared emulsion may be also threatened. This will leave at least one major project at the UK Schmidt unfinished, and 
I know there are many other long-term monitoring programs that depend on the 103a and IIa series.

So what does that leave?

Well, we still have IIIa-J and IIIa-F, and, as you have heard, great things are expected from Tech Pan, which is available on a film base. In view of the excellent properties of this material, I have also been pressing Kodak to produce a Tech Pan-type emulsion with B or V sensitivity.

This is not as hopeless a task as one might imagine, since many process and workroom films have this kind of restricted sensitivity, and Tech Pan-type products have properties which would be ideal for many large-scale commercial activities. Since I pointed out this possibility, I am aware that there has been some activity, but I cannot yet report any positive outcome.

My view is that Kodak should at least put some effort into Tech Pan B as a substitute for what has been lost. A product as versatile as Tech Pan that could be handled under a safelight would have much wider applications than astronomy.

As you will hear from the next speaker, there are other manufacturers of special emulsions for astronomy here in Germany, and I have recently tested a promising product from Russia, so all is not lost, provided we can solve some supply and distribution problems.

The final question remains. Is it worth persisting with photography? Of course. It is the only detector available in virtually unlimited size, a fact which makes very good use of the huge focal planes of wide field telescopes. With a pixel size of about 5 microns and a quantum efficiency well in excess of $5 \%$, it is unlikely to be replaced for some time to come. But a bit of help from Kodak would not come amiss. 